\section{Commentary: Prime and prevent paraplegia}

\author{
Jacob Kriegel, MD, Virendra Patel, MD, and \\ Hiroo Takayama, MD, PhD
}

Paraplegia in patients is tragic. Thoracoabdominal aortic aneurysm surgery can be a cause. Reported rates of spinal cord ischemia and resultant paraplegia vary with the extent of aortic resection. The rate after open repair of Crawford type II aneurysm has been reported to be as high as more than $10 \%{ }^{1}$ Although the risk appears to be mitigated with endovascular stent-graft repair, it still happens in approximately $6 \%$ of patients. ${ }^{2}$

The spinal cord receives blood supply from multiple sources, including the branches off of named arteries, such as vertebral arteries, subclavian arteries, segmental arteries, and hypogastric arteries, as well as the paraspinous collateral network. Open thoracoabdominal aortic aneurysm procedure impairs spinal cord perfusion by reducing the systemic blood pressure (especially distal to the aortic clamp), increasing the drainage pressure, and temporarily or permanently terminating some of the inflow sources (eg, segmental arteries). Patient factors, such as extension of the preexisting aortic and iliac disease and previous history of aortic surgery, may further compromise the perfusion.

Preventive measures have been extensively studied and implemented. The systemic blood pressure may be augmented with induced proximal hypertension and distal perfusion, and the drainage pressure can be managed with cerebrospinal fluid drainage. Management of the segmental/intercostal arteries is as important. Honkanen and colleagues ${ }^{3}$ present spinal cord priming in a piglet model. In the priming group $(\mathrm{n}=6)$, sequential ligation of the 8 superior most segmental spinal arteries was performed in a stepwise fashion at 5-minute intervals, followed by aortic occlusion for 25 minutes. In the

From the Aortic Center, Columbia University Medical Center, New York, NY.

Disclosures: The authors reported no conflicts of interest.

The Journal policy requires editors and reviewers to disclose conflicts of interest and to decline handling or reviewing manuscripts for which they may have a conflict of interest. The editors and reviewers of this article have no conflicts of interest.

Received for publication Oct 14, 2020; revisions received Oct 14, 2020; accepted for publication Oct 15, 2020; available ahead of print Sept 12, 2020.

Address for reprints: Hiroo Takayama, MD, PhD, Aortic Center, Columbia University Medical Center, 177 Fort Washington Ave, MHB Suite 7-435, New York, NY 10032 (E-mail: ht2225@cumc.columbia.edu).

J Thorac Cardiovasc Surg 2022;164:810-1 0022-5223/ $\$ 36.00$

Copyright $₫ 2020$ Published by Elsevier Inc. on behalf of The American Association for Thoracic Surgery

https://doi.org/10.1016/j.jtcvs.2020.10.054

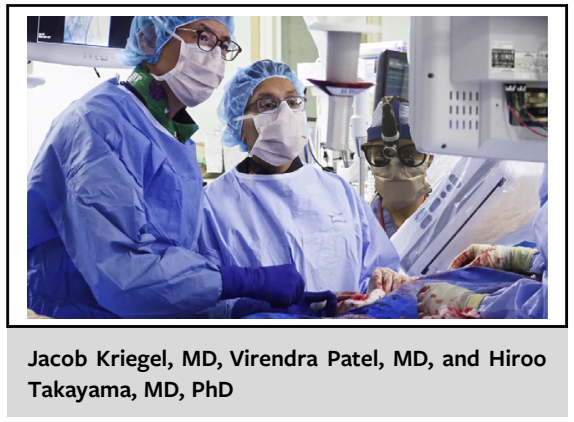

CENTRAL MESSAGE

This promising animal model

shows a profound influence of

timing in segmental artery liga-

tion on the development of the

postoperative paraplegia.

control group $(n=6)$, the aorta was first crossclamped and the 8 superior segmental spinal arteries were ligated within 5 minutes of aortic occlusion. At 5-day follow-up, $50 \%$ of the control animals developed paraplegia compared with $0 \%$ in the priming group. The perioperative motor-evoked potential assessment and histological study provided further supportive evidence of spinal protection with the priming. Here, acute sequential ligation of segmental arteries just before aortic crossclamping appears to have a beneficial effect.

Flow into the collateral network, which is an increasingly recognized important mechanism of spinal cord perfusion, is augmented in response to occlusion of feeder vessels. Selective ligation of these vessels has been posited to have a protective effect on the spinal cord, by increasing flow from other arterial feeders and reducing the risk of steal through the segmental vessels in the setting of a clamped and open aorta. ${ }^{4,5}$ A similar concept of ischemic preconditioning has been utilized with some success in preventing ischemic injury, but this effect has generally been assumed to be mediated by angiogenesis that takes days to weeks to manifest before surgery. ${ }^{6,7}$ The authors have developed a beautiful model that might be 1 further step toward a clinical benefit in these contexts; however, we know no aorta can be replaced using their model. The aorta was clamped on at 1 site, and was not opened at all.

The abyss of the valley between these experimental models and the actual clinical practice remains within the dense fog. We must keep trying. 


\section{References}

1. Coselli JS, LeMaire SA, Preventza O, de la Cruz KI, Cooley DA, Price MD, et al. Outcomes of 3309 thoracoabdominal aortic aneurysm repairs. J Thorac Cardiovasc Surg. 2016;151:1323-37.

2. Hu Z, Li Y, Peng R, Liu J, Jia X, Liu X, et al. Multibranched stent-grafts for the treatment of thoracoabdominal aortic aneurysms: a systematic review and metaanalysis. J Endovasc Ther. 2016;23:626-33.

3. Honkanen HP, Mustonen C, Herajärvi J, Tuominen H, Starck T, Kallio M, et al. Priming protects the spinal cord in an experimental aortic occlusion model. $J$ Thorac Cardiovasc Surg. 2022;164:801-9.e2.

4. Christiansson L, Ulus AT, Hellberg A, Bergqvist D, Wiklund L, Karacagil S. Aspects of the spinal cord circulation as assessed by intrathecal oxygen tension moni- toring during various arterial interruptions in the pig. J Thorac Cardiovasc Surg. 2001;121:762-72.

5. Griepp RB, Griepp EB. Spinal cord perfusion and protection during descending thoracic and thoracoabdominal aortic surgery: the collateral network concept. Ann Thorac Surg. 2007;83:S865-9.

6. Luehr M, Salameh A, Haunschild J, Hoyer A, Girrbach FF, von Aspern K, et al. Minimally invasive segmental artery coil embolization for preconditioning of the spinal cord collateral network before one-stage descending and thoracoabdominal aneurysm repair. Innovations (Phila). 2014;9: $60-5$.

7. Simon F, Wagenhäuser MU, Busch A, Schelzig H, Gombert A. Arteriogenesis of the spinal cord-the network challenge. Cells. 2020;9:501.
See Article page 801.

\section{Commentary: Determining the role of priming for spinal cord protection during open aneurysm surgery: Have we used the right model?}

\author{
Harold L. Lazar, MD
}

Spinal cord injury (SCI) is the Achilles' heel of thoracic and thoracoabdominal aneurysm (TAA) surgery performed by either an open or thoracic endovascular aneurysm repair (TEVAR). It results in increased morbidity and mortality and, more importantly, contributes to a marked reduction in quality of life. The introduction of neuroprotective adjuvant strategies that increase spinal cord perfusion and reduce metabolism and oxygen demands have now become the standard of care in both open and TEVAR TAA procedures and have significantly reduced the incidence of perioperative $\mathrm{SCI} .{ }^{1-4}$

\footnotetext{
From the Division of Cardiac Surgery, Boston University School of Medicine, Boston, Mass.

Disclosures: The author reported no conflicts of interest.

The Journal policy requires editors and reviewers to disclose conflicts of interest and to decline handling or reviewing manuscripts for which they may have a conflict of interest. The editors and reviewers of this article have no conflicts of interest.

Received for publication Oct 3, 2020; revisions received Oct 3, 2020; accepted for publication Oct 5, 2020; available ahead of print Sept 18, 2020.

Address for reprints: Harold L. Lazar, MD, Division of Cardiac Surgery, Boston University School of Medicine, 80 E Concord St, Boston, MA 02118 (E-mail: harold.1. lazar@gmail.com).

J Thorac Cardiovasc Surg 2022;164:811-3

$0022-5223 / \$ 36.00$

Copyright (c) 2020 by The American Association for Thoracic Surgery

https://doi.org/10.1016/j.jtcvs.2020.10.011
}

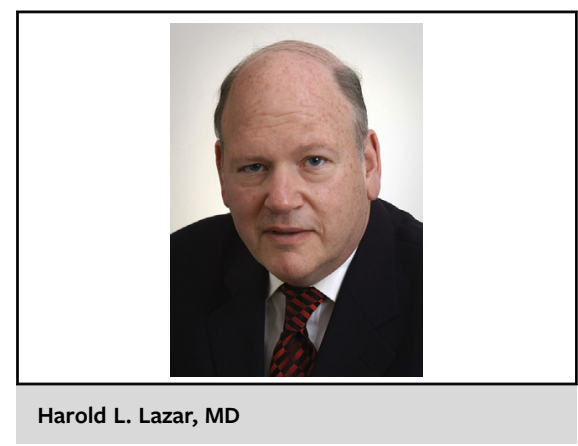

CENTRAL MESSAGE

Priming before open TAA repair

may limit spinal cord injury, but a

more relevant model is needed

to determine its role in clinical

practice.

Nevertheless, the incidence of SCI has not been totally eliminated and has been reported to average $8.26 \%$ (3.6\% paresis and 5.0\% paraplegia) for open TAA repairs ${ }^{5}$ and $12 \%$ for TEVAR ( $4 \%-8 \%$ paraplegia). ${ }^{6}$ This has led to the development of other strategies to reduce the incidence of SCI following TAA procedures. O'Callaghan and colleagues ${ }^{7}$ demonstrated that a staged TEVAR approach reduced the incidence of SCI from $37 \%$ to $11 \%$ $(P=.03)$. In this series, the interval between stages averaged 5 months. Whereas staged procedures may reduce the incidence of SCI, there is concern for the combined morbidity and mortality of 2 separate surgeries, as well as the possibility of death during the interval period between the 2 procedures. Furthermore, patients with multiple comorbidities and those who develop a complication following the first procedure may never complete the 